\title{
Effect of electrical stimulation on the production of cutaneous excreta by the earthworm Lumbricus terrestris $\mathrm{L}$
}

\author{
Manuscrit reçu le 8 avril 2020 et accepté le 4 juin 2020 \\ RAOUANE Mohammed* and El HARTI Abdellatif
}

\begin{abstract}
Reserch Team : Lumbricidae, Improving Soil Productivity and Environment (LAPSE), Centre « Eau, Ressources Naturelles, Environnement et Développement Durable (CERNE2D) » Mohammed V University in Rabat, École Normale Supérieure (ENS). Avenue Med Belhassan El Ouazani. BP 5118, Takaddoum-Rabat (Morocco).
\end{abstract}

\begin{abstract}
Cutaneous excreta of earthworms are an increasing interest in many areas of scientific research. Our study aims to develop an electrical technique for stimulating the production of these cutaneous excretions more efficient and less harmful than that using chemical stimulation with petroleum ether. This study made it possible to define the optimal electrical parameters ensuring the obtaining of a maximum rate of excretion. These parameters are respectively: a voltage $(\mathrm{U})$ of $20 \mathrm{~V}$, a pulse frequency $(\mathrm{F})$ of 100 stimulations per second and a stimulation time (T) of 5 minutes. The comparative study of this new technique of electrical stimulation compared to chemical stimulation shows statistically very comparable excretion production rates $(\mathrm{p}<0,05)$. However, electrical stimulation offers considerable advantages relating to the physical integrity of the worms (lower mortality rate than that obtained during chemical stimulation), the short duration of stimulation and the ease of recovery of sticky excretions. In addition, the electrical stimulation technique offers the possibility of reusing the worms in other electrical stimulations after a rest period of 3 weeks.
\end{abstract}

Key words: Cutaneous excreta, Electrical stimulations, Chemical stimulation, Earthworms, Lumbricus terrestris

\section{Résumé}

Les excrétions cutanées des vers de terre présentent un intérêt de plus en plus grandissant dans de nombreux domaines de la recherche scientifique. Notre étude a pour but la mise au point d'une technique électrique pour la stimulation de la production de ces excrétions cutanées plus performante et moins nocive que celle utilisant la stimulation chimique à l'éther de pétrole. Cette étude a permis de définir les paramètres électriques optimaux assurant l'obtention d'un taux d'excrétions maximal par la stimulation électrique. Ces paramètres sont respectivement : une tension (U) de $20 \mathrm{~V}$, une fréquence d'impulsions (F) de 100 stimulations par seconde et un temps de stimulation $(\mathrm{T})$ de 5 minutes. L'étude comparative de cette nouvelle technique de stimulation électrique par rapport à la stimulation chimique montre des taux de production d'excrétions statistiquement très comparables $(p<0,05)$. Cependant, la stimulation électrique offre des avantages considérables relatifs à l'intégrité physique des vers (taux de mortalité plus faible que celui obtenu lors de la stimulation chimique), à la courte

\footnotetext{
${ }^{*}$ Correspondence should be addressed to Raouane Mohammed ; mohamed raouane@yahoo.fr
} 
durée de stimulation et à la facilité de récupération des excrétions gluantes. En plus, la technique de stimulation électrique offre la possibilité de réutilisation des vers dans d'autres stimulations électriques après un temps de repos de 3 semaines.

Mots clés : Excrétions cutanées, stimulations électriques, stimulation chimique, vers de terre, Lumbricus terrestris

\section{Introduction}

Earthworms play a fundamental role in improving soil fertility. The activity of these burrowing animals optimizes the physicochemical and biological characteristics of the rhizosphere, resulting in improved plant productivity (Satchell, 1958 ; Lee, 1985 ; Edwards and Bohlen, 1996). The majority of studies agree that this inimitable role is attributable to the intestinal transit of soil and the flora associated with the worm's gut digestive tract (Schramm et al, 2003; Singleton et al, 2003 and Horn et al, 2006). In this context, our laboratory has focused its investigations on the contribution of cutaneous excreta in this fertility. In order to avoid any possible interference with soil constituents, it was necessary to first develop a method of stimulating the production of cutaneous excreta in earthworms in order to study their direct effects in vitro (El Harti et al., 2001a). Using this stimulation method, we have demonstrated that cutaneous excreta contains indole compounds that directly stimulate plant root production (El Harti et al., 2001a ; El Harti et al., 2001b). These rhizogenic substances are accumulated in the coelomic cavities of the worms and then released externally with the coelomic fluid via the coelomic pores (El Harti and Raouane, 2008; 2009). In other studies, we have demonstrated the neutralizing effect of these excretions on the $\mathrm{pH}$ of acidic and basic solutions. The excretions contribute to the regulation of soil $\mathrm{pH}$ and, consequently, root absorption of minerals (Raouane et El Harti, 2016 a; 2016 b).

The cutaneous excreta stimulation method usually used by our laboratory is qualified as chemical because it uses petroleum ether as a stimulus. This method is limited by its harmfulness to worms. The quantity of excreta recovered is also insufficient for chemical analyses and repetitive biological tests necessary for statistically robust studies. This chemical method also has some disadvantages related to the duration of stimulation and the difficulty of recovering these sticky excreta.

The present work targets development of an alternative technique based on electrical stimulation with the aim of improving the quantity of excreta recovered and reducing the toxic effect of stimulations on worms. Some laboratories already use electricity for a range of purposes. These include the use of electric current for collecting worms in the field (Staddon et al; 2003) and to extract coelomocytes (Massicotte et al., 2003 ; Hendawi et al., 2004 ; Belmeskine et al., 2012). Zhang et al. (2003) used an electric current to recover mucus to study the physicochemical characteristics in order to understand the ease of movements of worms in the soil. We first determine the optimal electrical parameters (voltage, frequency and stimulation time) allowing for recovery of a maximum volume of cutaneous excreta and limiting physiological harm to the worms. In a second step, we compare the efficiency and reliability of this new technique with the chemical method. Finally, we tested the ability of earthworms that had undergone a first electrical stimulation to reproduce these excretions 
after a second stimulation. This last test is carried out after a rest period of 3 weeks necessary for the worms to reconstitute these excretions.

\section{Materials and methods}

\subsection{Biological material}

Earthworm Lumbricus terrestris were harvested from fallow land near the lake formed by the reservoir of the Sidi Mohammed Ben Abdellah dam near Rabat, Morocco. All of the earthworms collected were adults with a clitellum.

\subsection{Experimental protocol}

For both stimulation techniques (electrical and chemical stimulation), the same protocol was followed before (pre-stimulation stage) and after (post-stimulation stage) the stimulation (stimulation stage sensu stricto). For each experiment, five lots of worms were used. Each lot consisted of five adult specimens (clitellum) with comparable average size and fresh weight. The term "cutaneous excreta" (CE) refers to all body fluids that released by the body surface of the worms as a result of external stimulus. These excreta consist of mucus released by the micropores, the coelomic fluid emitted by the coelomic pores, and the urine released by the nephridiopores. These $\mathrm{CE}$ are recoverable by rinsing the worms in distilled water. The quantity of $\mathrm{CE}$ was deduced by the difference of in fresh weights of worms before and after stimulation.

\subsubsection{Pre-stimulation stage}

First the earthworms were subject to fasting. The earthworms were kept for 8 days in terracotta pots lined with moistened cotton cloth. The tissue was replaced with a new one every 2 days until exhaustion of the solid droppings, which usually occurred around the eighth day. The fasting of the worms made it possible to exclude the excrement in the variation of weights during the weighting before and after the stimulations.

The worms were then rinsed, dried, and weighed. Just before the stimulation, each lot of worms was rinsed in 2-3 baths of distilled water and then dried quickly and delicately by winding in Joseph paper. The worms were then weighed on a precision balance. The weight thus obtained was considered as the initial fresh weight (FWi) of the lot of worms before stimulation.

\subsubsection{Stimulation stage sensu stricto}

After the pre-stimulation stages, the lots of worms were ready for electrical or chemical stimulation.

For the electrical stimulations, each lot of earthworms was introduced into a wide-mouth $30 \mathrm{~mL}$ bottle containing $5 \mathrm{~mL}$ of distilled water. The water acted as a conductor of electrical current and allowed recovery of the sticky cutaneous excreta by dissolution. The bottle was sealed with a rubber stopper adapted with two orifices that allowed the introduction of the two electrodes of a stimulator of the "double pulse stimulator" type. The effect of the variation in three electrical parameters were studied: the voltage of the current (U) expressed in volts, the 
frequency (F) or number of electrical stimulations per second (sti/s), and the total duration of stimulation expressed in minutes $(\mathrm{T})$.

Three series of experiments each consisting of 5 lots of worms were conducted to evaluate the effect of varying the voltage $(U)$ :

$$
\begin{aligned}
& \text { - A series }(\mathrm{a} 1, \ldots, \mathrm{a} 5): \text { effect at } U=5 \mathrm{~V} \\
& \text { - B series }(\mathrm{b} 1, \ldots, \mathrm{b}) \text { ): effect at } U=15 \mathrm{~V} \\
& \text { - C series }(\mathrm{c} 1, \ldots ., \mathrm{c} 5): \text { effect at } U=20 \mathrm{~V}
\end{aligned}
$$

In series $\mathrm{A}-\mathrm{C}$, the frequency and the total stimulation duration were set to $20 \mathrm{sti} / \mathrm{s}$ and $1 \mathrm{~min}$, respectively. Preliminary tests indicated that worms produced quantifiable $\mathrm{CE}$ at these minimum values. These same preliminary tests also indicated that the application of a voltage greater than $20 \mathrm{~V}$ caused the tetanization of the worms.

Three series of experiments each consisting of 5 lots of worms were conducted to evaluate the effect of varying the frequency of the stimulations $(\mathrm{F})$ :

$$
\begin{aligned}
& \text { - D series }(\mathrm{d} 1, \ldots, \mathrm{d} 5): \text { effect at } F=20 \mathrm{sti} / \mathrm{s} \\
& \text { - E series }(\mathrm{e} 1, \ldots, \mathrm{e} 5): \text { effect at } F=60 \mathrm{sti} / \mathrm{s} \\
& \text { - F series }(\mathrm{f} 1, \ldots, \mathrm{f} 5): \text { effect at } \mathrm{F}=100 \mathrm{sti} / \mathrm{s}
\end{aligned}
$$

Taking into account the results of the voltage experiment, voltage was fixed to a minimum value of $5 \mathrm{~V}$ for series $\mathrm{D}-\mathrm{F}$. The stimulation time was maintained at the minimum value of 1 $\min$.

To evaluate the effect of varying the total stimulation time (T), $\mathrm{T}$ was increased in $1 \mathrm{~min}$ intervals from $1 \mathrm{~min}$ to $6 \mathrm{~min}$. We used 5 lots of worms for each duration. The voltage and frequency of stimulations were set at their respective optimum values observed in the previous series of experiments $(\mathrm{U}=20 \mathrm{~V}, \mathrm{~F}=100 \mathrm{sti} / \mathrm{s})$.

- $\mathrm{G}$ series $(\mathrm{g} 1, \ldots, \mathrm{g} 5)$ : effect at $\mathrm{T}=1 \mathrm{~min}$

- $\mathrm{H}$ series $(\mathrm{h} 1, \ldots, \mathrm{h} 5)$ : effect at $\mathrm{T}=2 \mathrm{~min}$

- $\mathrm{K}$ series $(\mathrm{k} 1, \ldots, \mathrm{k} 5)$ : effect at $\mathrm{T}=3 \mathrm{~min}$

- L series $(11, \ldots, 15)$ : effect at $\mathrm{T}=4 \mathrm{~min}$

- $\mathrm{M}$ series $(\mathrm{m} 1, \ldots, \mathrm{m} 5)$ : effect at $\mathrm{T}=5 \mathrm{~min}$

- $\mathrm{N}$ series $(\mathrm{n} 1, \ldots, \mathrm{n} 5)$ : effect at $\mathrm{T}=6 \mathrm{~min}$

For the chemical stimulations, the technique of El Harti et al. (2001a) was used. After the prestimulation stage, each lot of Q series worms $(q 1, \ldots, q 5)$ was deposited in a crystallizer of 115 $\mathrm{mm}$ diameter with a container of petroleum ether in the centre. The crystallizer was hermetically sealed, and as soon as the atmosphere was charged with a volatile ether, the worms reacted vigorously, releasing abundant cutaneous excreta. The stimulation was stopped after about 10 to 15 minutes when the worms stopped reacting because of the anaesthetic effect of the ether. Note that the stimulation time depended on the volume of the crystalliser used in the chemical stimulation. 


\subsubsection{Post-stimulation stage}

As soon as the stimulation stage sensu stricto was complete, each lot of worms was removed, rinsed, and dried quickly as in the pre-stimulation stage. The rinsing and drying operation was necessary to remove the CE that persisted on the worms' body. In the end, each lot of worms was weighed and the value thus obtained was considered as the final fresh weight (FWf).

\subsubsection{Control of Electrical and Chemical Stimulation}

The series of worms $\mathrm{P}(\mathrm{p} 1, \ldots, \mathrm{p} 5)$ was the control. In this case the lots of worms were subject to the same experimental protocol except they were stimulated with electrical current or petroleum ether. The objective was to compare series $\mathrm{P}$ to the stimulated lots of worms to control for the extreme sensitivity of worms that reacted by releasing excreta during the rinsing and drying of the pre-stimulation and post-stimulation stages.

\subsubsection{Observation of worms after stimulation}

The aim of this experiment was to determine the impact of both types of stimulation on worms. Three series of worms were used. Each series consisted of three lots and each lot consisted of 20 adult specimens of approximately the same weight. We used the same experimental protocol described previously. The first series had optimal electrical stimulation, while the second series had chemical stimulation. The third series was a control and was not subject to any stimulation. After treatment, all worms from the three series were enclosed in pots filled with soil from the worm's collection site. The three series of worms were fed for three weeks with oat bran and potato peel. Observations were made each week to compare the impact of the two types of stimulation on mortality and worm health. The series of worms not subject to stimulation provided a control for the effect of captivity. Surviving worms after 3 weeks of captivity were subjected to a second electrical or chemical stimulation. The results of the quantities of $\mathrm{CE}$ obtained were compared with those obtained during the first stimulation.

\subsection{Evaluation of cutaneous excreta quantities and statistical analysis}

The difference between FWi and FWf of each lot corresponds to the fresh weight of the CE released during the electrical or chemical stimulation. Since the initial fresh weights of worms in different experimental series were not equal, we standardized the expressed fresh weight of excreta as a percentage of the initial fresh weight of the lot considered.

For each experimental series, the average percentage of CE was used in the comparison of results. Differences among treatments were analysed with an anova test followed by the Tukey HSD post-hoc test. Statistical analyses were performed using SPSS software (IBM Corp Version 22). Differences were considered significant when $p<0.05$.

\section{Results and discussion}

The experiments conducted during this study demonstrate the extreme excitability of earthworms since every lot of worms reacted to the electrical or chemical stimulus. This reaction manifested as worm agitation, which was a function of the intensity of the stimulus. 
These movements were accompanied by a greater or lesser quantity of mucus that envelops the entire body of the worms. This mucus can even be a jelly in which the worms are housed when the stimulus was especially strong. In addition to mucus, the stimulation of worms caused the release of the coelomic fluid with a yellow colour, and was excreted through the coelomic pores all along their bodies. Indeed, the worms' agitation caused the compression of the coelomic cavities, expelling their contents. The reactivity of worms to electrical stimulation was immediate with all parameters tested. However, their reactivity was slower and progressive when chemical stimulation was applied. With chemical stimulation, the worms react intensively after five to seven minutes when the ambient air of the enclosure was charged with volatile petroleum ether.

\subsection{Effect of electrical stimulation parameters on the production of $\mathrm{CE}$}

Figure 1 illustrates the progression of CE in Lumbricus terrestris as a function of the voltage (U) of the electric current (series A, B and C). There was a clear correspondence between U and the production of $\mathrm{CE}$. The quantity of secretion varied from $1.84 \%$ at $5 \mathrm{~V}$ to $2.78 \%$ at 20 $\mathrm{V}$. The average quantity of secretion in the control group did not exceed $1.16 \%$. Electrical stimulation with a voltage greater than $20 \mathrm{~V}$ caused tetanization of the worms. The Tukey comparison tests revealed significant differences between the control lots and the lots stimulated by a current of $5 \mathrm{~V}, 15 \mathrm{~V}$, and $20 \mathrm{~V}$ (series A, series B, and series C, respectively). Also he revealed a significant difference between all stimulated lots.

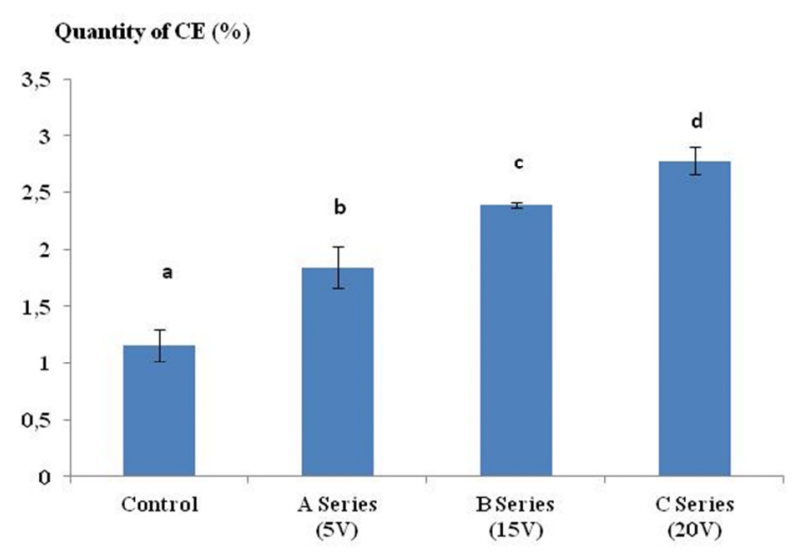

Figure 1:. Quantity of cutaneous excreta (CE) released (\%) by Lumbricus terrestris as a function of the voltage of the electric current applied. Bars with the same letter indicate that they were not significantly different (Tukey, $p<0.05$ ).

Figure 2 illustrates the variation of quantity of $\mathrm{CE}$ as a function of the frequency (F) of electric shocks (series D, E, and F). The secretion quantity varied from $1.89 \%$ for a frequency of $20 \mathrm{sti} / \mathrm{s}$ to $5.79 \%$ when the frequency reached $100 \mathrm{sti} / \mathrm{s}$. Frequencies greater than $100 \mathrm{sti} / \mathrm{s}$ caused damage similar to that caused by voltage higher than $20 \mathrm{~V}$. The Tukey test indicated that series F (100 sti/s) was significantly different from both the control and series D (20 
$\mathrm{sti} / \mathrm{s})$. Series E (60 sti/s) was not significantly different from any of the other series (control, D series, and F series).

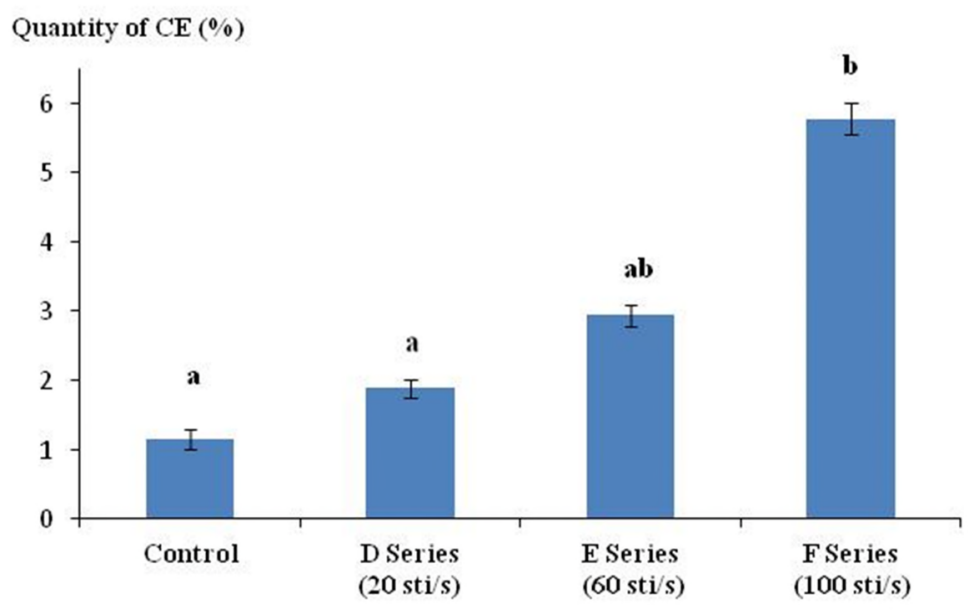

Figure 2: Quantity of cutaneous excreta (CE) released (\%) by Lumbricus terrestris as a function of the frequency of electrical stimuli (sti/s). Bars with the same letter indicate that they were not significantly different (Tukey, $\mathrm{p}<0.05$ ).

Figure 3 illustrates that the quantity of $\mathrm{CE}$ increased as the duration of stimulation was prolonged to a maximum of 5 minutes. Excretions decreased in lots of worms exposed to the electrical stimulus for 6 minutes and can be explained by the long immersion time of the worms in the distilled water. It was possible that the worms absorbed some of the water causing weight gain and reducing the difference between final and initial fresh weights. The Tukey comparison test indicates a significant difference between all groups. Only the group $\mathrm{N}$ (6 min) is not significantly different from the group $\mathrm{H}$ (2 min) and $\mathrm{K}$ (3 min).

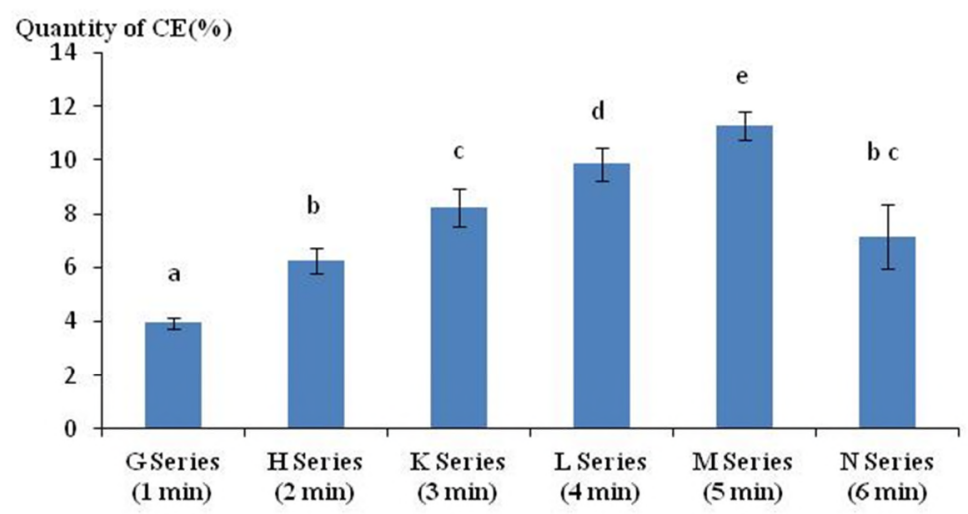

Figure 3: Quantity of cutaneous excreta (CE) released (\%) by Lumbricus terrestris as a function of electrical stimulation time. Bars with the same letter indicate that they were not significantly different (Tukey, $\mathrm{p}<0.05$ ). 
The results obtained in the previous experiments allowed us to define the optimal conditions for harvesting maximum CE. Optimal conditions were a voltage $20 \mathrm{~V}$, a stimulation frequency of 100 pulses per second, and a duration of 5 minutes.

\subsection{Comparison between electrical and chemical stimulation of $\mathrm{CE}$ production}

The chemical stimulation method with petroleum ether, often used by our laboratory during previous work, provided CE in comparable quantities to that obtained by the electrical stimulation method once conditions were optimized. The quantity of CE obtained by chemical and electrical stimulation was $12.27 \%$ and $11.27 \%$, respectively (Figure 4), but standard deviation with chemical stimulation was much larger. The difference between the quantities obtained by the two stimulation methods was not significantly different. However electrical stimulation did provide some benefits. Advantages of the electrical stimulation method were the speed of the stimulation operation ( 5 minutes versus 15 minutes minimum) and the easy recovery of CE worms that were released directly into the immersion medium. Indeed, CE of earthworms stimulated with the chemical method without any immersion tended to clump along the body of the worms and required a lot of water for recovery.

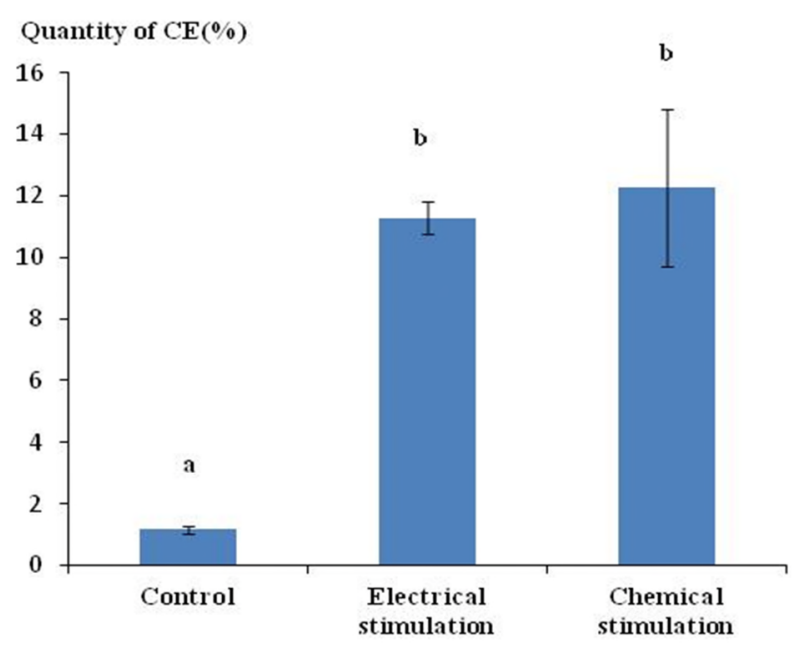

Figure 4: Quantity of cutaneous excreta recovered (\%) from Lumbricus terrestris stimulated using two different methods (electrical or chemical). Bars with the same letter indicate that they were not significantly different (Tukey, $\mathrm{p}<0.05$ ).

\subsection{Impact of electrical and chemical stimulation on the worms}

The cumulative mortality percentages of worm lots monitored over a period of 3 weeks are presented in Table 1. A much higher average cumulative mortality percentage was observed for lots subjected to chemical stimulation $(46.6 \%)$ relative to electrical stimulation $(5.0 \%)$. The control lots experienced zero mortality, indicating that Lumbricus terrestris tolerates the conditions of captivity for at least three weeks. The mortality observed in the lots that were stimulated is linked to the stimulations. In addition, earthworms from lots that had electrical stimulation and were captive for observation were electrically stimulated for the second time 
under optimal conditions. In these cases, the secretion quantities were comparable to those obtained during the first stimulation. These values varied between $10 \%$ and $12 \%$, but in these cases the secretions were less viscous suggesting that the proportion of sticky mucus was lower in the second series of stimulation. Surviving chemically stimulated worms have not undergone a second chemical stimulation since their mortality percentages is very high.

Table 1: Effect of Electrical and Chemical Stimulation on L.terrestris mortality rate

\begin{tabular}{|c|c|c|c|}
\hline & \multicolumn{3}{|c|}{ Cumulative mortality percentage (\%) } \\
\hline & Control & Electrical stimulation & Chemical stimulation \\
\hline \multirow{3}{*}{ Week 1} & \multirow{3}{*}{0} & Lot $1: 0$ & Lot $1: 15$ \\
\hline & & Lot 2: 0 & Lot 2: 25 \\
\hline & & Lot 3: 0 & Lot 3: 10 \\
\hline \multirow{3}{*}{ Week 2} & \multirow{3}{*}{0} & Lot 1: 0 & Lot 1: 15 \\
\hline & & Lot 2: 0 & Lot 2: 40 \\
\hline & & Lot 3: 10 & Lot 3: 25 \\
\hline \multirow{3}{*}{ Week 3} & \multirow{3}{*}{0} & Lot $1: 5$ & Lot 1: 50 \\
\hline & & Lot 2: 0 & Lot 2: 60 \\
\hline & & Lot 3: 10 & Lot 3: 30 \\
\hline $\begin{array}{c}\text { Average } \\
\text { mortality after } \\
3 \text { weeks }\end{array}$ & $\mathbf{0}$ & 5.0 & 46.6 \\
\hline
\end{tabular}

\section{Conclusion}

Earthworms are a critical component of the soil fauna. They continuously produce a considerable quantity of $\mathrm{CE}$ when active. Our laboratory has focused its research on the impacts of these excretions to the rhizosphere. Indeed, in vitro studies have shown the presence of indole compounds in CE that stimulate root formation in plants (El Harti et al., 2001a ; El Harti et al., 2001b). These rhizogenic compounds accumulate in the coelomic fluid before they are released from the coelomic pores (El Harti and Raouane, 2008; 2009). Other in vitro studies have revealed that $\mathrm{CE}$ has a neutralizing effect on both acidic and basic solutions (Raouane et El Harti, 2016 a; 2016 b). These works were all carried out using excreta obtained through chemical stimulation. As previously reported, this type of stimulation can harm earthworms.

Our interest to the CE has led us to develop a stimulation technique for optimal recovery of these excretions. The electrical stimulation adopted and presented in this work was effective when compared to chemical stimulation. It is faster, causes less harm to worms, and allows for easy recovery of excretions.

Cutaneous excreta naturally produced by earthworms and by other organisms such as molluscs (e.g., slugs, snails) are of increasing interest because of their potential applications in biological, medical, and cosmetic fields (Pawlicki et al., 2003; Bonnemain, 2005; El Mubarak et al.,2013 ; Kantawong et al., 2016 ;). The new technique presented here is less harmful and more practical, and it could be adapted to other organisms for recovering 
sufficient quantities of CE. Our laboratory will adopt this new technique for our future research.

\section{References}

Belmeskine, H., Haddad, S., Vandelac, L., Sauvé, S., and Fournier, M., 2012. Toxic effects of PCDD/Fs mixtures on Eisenia andrei earthworms. Ecotoxicology and Environmental Safety. 80: 54-59.

Bonnemain, B., 2005. Helix and drugs: snails for western health care from antiquity to the present. Evid Based Complement Alternat Med. 2: 25-28.

Dubilier, N., 2003. Acidovorax-like symbionts in the nephridia of earthworms. Environ Microbiol. 5: 804-809.

Edwards, C.A., and Bohlen, P.J., 1996. Biology and Ecology of Earthworms. Chapman and Hall, London.

El Harti, A., Saghi, M., Molina, J.A.E., and Teller, G., 2001a. Production d'une substance rhizogène à effet similaire à celui de l'acide indole acétique par le ver de terre Lumbricus terrestris. Canadian Journal of Zoology. 79(11): 1911-1920.

El Harti, A., Saghi, M., Molina, J.A.E., Teller, G., 2001b. Production de composés rhizogènes par le ver de terre Lumbricus terrestris. Canadian Journal of Zoology. 79(11): 1921-1932.

El Harti, A., and Raouane, M., 2008. Détermination des sites de production et d'accumulation des composés indoliques chez Lumbricus terrestris. Bulletin de la Société Royale des Sciences de Liège, Vol. 77: 62-79 https://popups.uliege.be:443/0037-9565/index.php?id=575

El Harti, A., and Raouane, M., 2009. Détermination de la région d'excrétion des substances rhizogènes chez Lumbricus terrestris L. Biotechnol. Agron. Soc. Environ. 13(1): 85-92.

El Mubarak, M.A.S., Lamari, F.N., and Kontoyannis, C., 2013. Simultaneous determination of allantoin and glycolic acid in snail mucus and cosmetic creams with high performance liquid chromatography and ultraviolet detection. J. chromatography A. 1322: 49-53.

Hendawi, M., Sauvé, S., Ashour, M., Brousseau, P., and Fournier, M., 2004. A new ultrasound protocol for extrusion of coelomocyte cells from the earthworm Eisenia fetida. Ecotoxicology and Environmental Safety. 59: 17-22.

Kantawong, F., Thaweenan, P., Mungkala, S., Tamang, S., Manaphan, R., Wanachantararak, P., E-Kobon, T., and Chumnanpuen, P., 2016. Mucus of Achatina fulica stimulates mineralization and inflammatory response in dental pulp cells. Turk J Biol. 40: 353-359. 
Massicotte, R., Robidoux, P.Y., Sauvé, S., Flipo, D., Fournier, M., and Trottier, B., 2003. Immune response of earthworms (Lumbricus terrestris, Eisenia andrei and Aporrectodea tuberculata) following in situ soil exposure to atmospheric deposition from a cement factory. J. Environ. Monit. 5(5): 774-779.

Pawlicki, J.M., Pease, L.B., Pierce, C.M., Startz, T.P., Zhang, Y., and Smith, M., 2003. The effect of molluscan glue proteins on gel mechanics. The Journal of Experimental Biology. 207: 1127-1135.

Raouane, M., and El Harti, A., 2016a. Pouvoir neutralisant des pH acides par les excrétions cutanées de Lumbricus terrestris L. Bulletin de la Société Royale des Sciences de Liège. 85: 1-16. https://popups.uliege.be:443/0037-9565/index.php?id=5063

Raouane, M., and El Harti, A., 2016b. Effet neutralisant in vitro des $\mathrm{pH}$ basiques par les excrétions cutanées de Lumbricus terrestris. Bulletin de la Société Royale des Sciences de Liège. 85: 209-224.

https://popups.uliege.be:443/0037-9565/index.php?id=6310 DOI: https://doi.org/10.25518/0037-9565.6310

Satchell, J.E., 1958. Earthworm biology and soil fertility. Soils Fert. 21: 209-219. Lee, K.E., 1985. Earthworms: Their Ecology and Relationships with Soils and Land Use. Academic Press, London.

Schramm, A., Davidson, S.K., Dodsworth, J.A., Drake, H.L., Stahl, D.A., and Horn, M.A., Mertel, R., Gehre, M., Kästner, M., and Drake, H.L., 2006. In vivo emission of dinitrogen by earthworms via denitrifying bacteria in the gut. Appl. Environ.

Microbiol. 72: 1013-1018.

Singleton, D.R., Hendrix, P.F., Coleman, D.C., and Whitman, W.B., 2003. Identification of uncultured bacteria tightly associated with the intestine of the earthworm Lumbricus rubellus (Lumbricidae; Oligochaeta). Soil Biology \& Biochemistry. 35: 1547-1555.

Staddon, P.L., Ostle, N., and Fitter, A.H., 2003. Earthworm extraction by electroshocking does not affect canopy $\mathrm{CO} 2$ exchange, root respiration, mycorrhizal fungal abundance or mycorrhizal fungal vitality. Soil Biology and Biochemistry. 35(3): 421-426.

Zhang, D., Chen, Y., Ma, Y., Guo, L., Sun, J., and Tong, J., 2016. Earthworm epidermal mucus: Rheological behavior reveals drag-reducing characteristics in soil. Soil \& Tillage Research. 158: 57-6. 